Article

\title{
Hotel Overbooking and Cooperation with Third-Party Websites
}

\section{Yufeng Dong * and Liuyi Ling}

School of Management, University of Science \& Technology of China, Jinzhai Road 96, Hefei 230026, China; E-Mail: lyling@ustc.edu.cn

* Author to whom correspondence should be addressed; E-Mail: dyf2010@mail.ustc.edu.cn; Tel.: +86-551-6360-7902.

Academic Editor: Marc A. Rosen

Received: 22 April 2015 / Accepted: 17 August 2015 / Published: 25 August 2015

\begin{abstract}
Hotels cooperate with third-party websites to enhance their competitive position and attain sustainable development in the era of e-commerce. Furthermore, hotel managers overbook to hedge against last-minute cancellations and customer no-shows. This paper discusses pricing and overbooking strategies of a hotel in the context of cooperation with multiple third-party websites and analyzes how these strategies influence the cooperation process. The increase in profits resulting from the overbooking strategy is also examined. A model of a Stackelberg game between the hotel and third-party websites and a Nash game among the third-party websites are developed to analyze the process. Results indicate that the compensation coefficient has a slight influence on hotel pricing strategy, but causes a sharp decrease in overbooking level. As the hotel demands to lessen the probability of denying under higher compensation rate, the third-party websites would exert less sales effort to reduce the demand of online customers. Results also show that under a given market demand, hotel effort only serves to redistribute market shares among the hotel and third-party websites, without influencing hotel pricing and overbooking decisions. Specifically, the market shares of the third-party websites decrease in the effort level of the hotel resulting from an increase in the hotel market share. Finally, in the numerical example where one hotel and two websites are analyzed, hotel overbooking strategy improves hotel profit by $4.20 \%$, whereas profit improvements for Websites 1 and 2 are as high as $5.26 \%$ and $5.21 \%$, respectively. Managerial implications of the study are also provided.
\end{abstract}

Keywords: pricing; overbooking; online distribution; hotel; third-party website 


\section{Introduction}

In the hospitality industry, some customers may cancel their reservations before the target date or fail to show up without prior notification [1,2]. Unlike tangible goods, hotel rooms are perishable [3-5]; that is, when a reservation is suddenly cancelled, it is difficult to obtain a customer to occupy the hotel room in time. Consequently, hoteliers lose income if the hotel room becomes unoccupied. This distinguishing characteristic results in a zero salvage value to hotel rooms, because unoccupied rooms do not generate any revenue for hoteliers and cannot be reflected in the inventory for future use $[6,7]$. On the other hand, managing hotel rooms incurs a high fixed cost but a relatively low variable cost, leading to considerable marginal profits for hoteliers [7,8]. By contrast, hotels suffer heavy revenue loss from last-minute cancellations and customer no-shows.

Hotels reduce this loss by adopting overbooking strategy to ensure full room occupancy and to maintain a high occupancy rate [9-11]. Overbooking is defined as selling more rooms than hotel capacity, which is performed when a certain number of booked customers are anticipated to cancel or not to show up [12]. As a functional component of revenue management application, overbooking generates as high as $20 \%$ of the total revenue opportunity for hotels [13,14].

The occupancy rates of hotel rooms will increase because of overbooking [15]. However, if the number of customers with last-minute cancellations and no-shows is extremely small, the number of arrivals may exceed hotel capacity. When hotels cannot accommodate all arrivals at a target date, they will suffer losses because of compensation for the inconvenience of denied customers, loss of goodwill, and operating constraints $[14,16]$. Hence, determining the balance between the benefits and harm in implementing overbooking strategy is important. This study aims to address this issue.

Grönroos [17] stresses the significance of service marketing in the marketing area and gives a cutting-edge interpretation on the service marketing theory. Due to the changes in the world economy and business practice, services dominate the modern economies of the world, and Zeithaml et al. [18] suggest that mangers should consider service marketing as a competitive business imperative. In recent decades, the online distribution channel becomes prevalent and indispensable in the promotion of goods and services in the service industry [19-22]. Hotels facing intense competition will certainly embrace prevalent online booking requirements. In the process, they cooperate with third-party websites, such as Orbitz, Expedia, and eLong, to broaden their market demand. Specially, many hotels are unknown to the public and turn to well-known third-party websites to promote room selling. These third-party websites enable customers to search for different information on their trips and aid them in choosing the most suitable goods or services. Third-party websites also allow control for customers in the selection process and provide convenience. Therefore, hotels should cooperate with third-party websites to widen the market and enhance their competitive position, thereby ensuring their sustainable development $[23,24]$.

Many studies have been conducted on hotel overbooking strategy [25,26] or cooperation between hotels and third-party intermediaries [27-30]. The present paper develops a model to explore hotel pricing and overbooking strategies in the context of the cooperation between a hotel and multiple third-party websites. Hadjinicola and Panayi [31] observe that overbooking at the hotel level generates more cost savings than at each tour operator level when the hotel cooperates with multiple tour-operators. Thus, the present paper considers hotel room capacity as a whole, and formulates a 
single overbooking strategy for the hotel instead of multiple overbooking strategies for each third-party website separately. A Stackelberg game model is developed to explore the cooperation process between the hotel and third-party websites, while a Nash game is built among multiple third-party websites to describe their competitiveness on limited hotel rooms. The profit improvement for the hotel and third-party websites by overbooking strategy is then analyzed. This study seeks to answer the following questions: (1) What are the equilibrium decisions on hotel pricing and overbooking strategies and the effort level for the third-party websites? (2) What are the effects of compensation paid to a denied customer, demand fluctuation, hotel effort, and room capacity on optimal decisions? (3) How does the overbooking strategy of the hotel influence the cooperation process with the third-party websites? (4) How much profit improvement does a hotel overbooking strategy bring to the hotel and third-party websites?

Results presented in this paper are constructive. First, the compensation coefficient is observed to have a slight effect on optimal room rate, but causes a sharp decrease in the overbooking level because the hotel anticipates reducing the risk of over-sale. On the other hand, along with the increase in compensation coefficient, the third-party websites exert less effort in room sales to attract fewer customers as the hotel demands to lessen the probability of denying. Second, given the market demand, hotel effort will affect market shares of the hotel and cooperative third-party websites, but not hotel pricing and overbooking strategies. Specifically, the market shares of the third-party websites decrease in hotel effort level because of an increase in the market share of the hotel. Third, overbooking strategy brings profit increases of $5.26 \%$ and $5.21 \%$ for Websites 1 and 2, respectively, in the numerical example, but only $4.20 \%$ for the hotel. Therefore, third-party websites benefit more from the overbooking policy than the policy implementer, namely, the hotel. However, third-party websites that exert more effort to make sales do not always benefit more from the overbooking strategy.

The rest of paper is structured as follows: Section 2 reviews previous literature on the overbooking strategy in hotels and their cooperation with third parties, and addresses the research gap between previous studies and this paper. Section 3 describes the problem of hotel overbooking and cooperation with multiple third-party websites. A mathematical model is built and equilibrium solutions are derived. In Section 4, a numerical study is conducted to illustrate the effects of parameters on optimal decisions and profits. Section 5 explores how the overbooking strategy improves profits. Finally, Section 6 concludes this paper, provides some managerial implications, and highlights directions for future research.

\section{Literature Review}

\subsection{Hotel Overbooking Strategy}

Overbooking has long been a crucial lever for hotel revenue management [16,32-34]. Rothstein [35] is the first to develop a mathematical model to determine hotel overbooking level, and he suggests that hotel managers set overbooking limits at various decision points prior to the target date and optimize the overbooking problem by adjusting these limits. Ivanov [36] analyzes how optimal overbooking limits will change when a new booking request is received for a specific date, given the guaranteed and nonguaranteed reservations rate, which provides hotel managers with a simple operable methodology 
to control their room inventory when the guaranteed/nonguaranteed bookings ratio changes. Liberman and Yechiali [37] establish optimal overbooking level by maximizing the net profit of the hotel manager. In their paper, overbooking decisions are formulated by comparing the inventory level of confirmed reservations and the number of new requests. Toh [38] proposes a model that helps hotel managers to establish optimal booking levels systematically by balancing the opportunity cost of empty rooms with the adverse consequences of over selling. Toh and Dekay [39] also emphasize the importance of that balance in setting customer service levels to solve hotel overbooking problems. Koide and Ishii [40] maximize expected total sales by allowing customers paying the regular rate to make cancellations but not those with discounted rates. Therefore, the expected total sale is proved to be unimodal on the number of overbooking, indicating that the expected total sale is concave in the number of overbooking and the unique optimal overbooking level is obtained. Talluri and Van Ryzin [41] outline overbooking as one of the most successful revenue management practices. They build static as well as dynamic overbooking models to maximize the total volume of sales by balancing the negative effects of denying service against the rewards of increased sales.

In the hotel industry, one inventory class may be used as a substitute to satisfy the demand of another, which is known as an upgrade or a downgrade. Karaesmen and van Ryzin [42] discuss the overbooking problem by considering multiple reservations and inventory classes and jointly determine overbooking levels for the reservation classes.

Unlike the previous studies mentioned above, the present study develops a mathematical model to determine optimal overbooking levels by maximizing hotel revenue considering stochastic cancellation of customers in the context of cooperation with third-party websites. A similar study is conducted by Hadjinicola and Panayi [31]. However, their paper merely states that the overbooking strategy at the hotel level generates more cost savings than at the tour operator level by the method of data analysis. Obtaining the optimal overbooking level or monitoring the cooperation process between the hotel and tour operators is not performed in their paper.

\subsection{Cooperation with Third-Party Websites}

Online distribution channels enhance the promotion of goods and services in the service industry [19,21,22], among which OTA is one of the most important intermediaries and serves as web supermarket in air, hotels, rental car, and cruise lines marketing [43]. Medina-Muñoz and García-Falcón [24] seek to identify the determinants of successful relationships between hotels and travel agencies and claim that for a hotel, collaborating with other entities is the most cost-effective method for extending sales and marketing effort. Ling et al. [44] develop a pricing model between small- and medium-sized hotels and a third-party website, considering that these hotels are not likely to run websites of their own because of high costs. Beritelli [45] presents evidence on how to choose cooperative actors in tourism destinations. Huang et al. [46] outline how tour operators contribute to a tourism supply chain composed of multiple hotels and travel agencies. A number of other studies explore the cooperation between service providers and third parties from the perspective of a strategic alliance but not to the individual level [28-30].

All these studies emphasize the important role of third parties in hotel room marketing. However, third-party websites compete severely with hotels on customer source, which causes a problem of 
conflict of distribution channel for hotels [47,48]. Therefore, Xu et al. [49] optimize room allocation between hotels and third-party websites by first setting online-exclusive rooms for third-party websites, and then allowing the hotel to decide whether to accept additional requests from the website to maximize its profit. Lee et al. [50] examine the hostile relationship between OTAs and hotels taking the example of Choice Hotels International and Expedia.com and suggest hotel avoid overreliance on OTAs. In our paper, the hotel and cooperative third-party websites make effort independently to encourage customers to book rooms from their own distribution channels.

The present paper analyzes the cooperation and competition relationship between the hotel and multiple third-party websites simultaneously, and explores the effect of hotel decision on that of third-party websites.

\section{Problem Statement}

This paper discusses the cooperation problem between one hotel and $n$ third-party websites. To distribute its rooms online and widen its online market, the hotel cooperates with $n$ third-party websites on room sales. Considering some customers cancel their reservations very late or just do not show up at the target date without notifying the hotel, the hotel adopts an overbooking strategy and determines its overbooking level by taking account into stochastic cancellations of customers. The hotel is examined in terms of its overbooking level and room rate, whereas third-party websites are examined in terms of their sales effort.

\subsection{Cooperation between the Hotel and Third-Party Websites}

A hotel with $C$ identical rooms cooperates with $n$ third-party websites on room booking service to improve its occupancy rate. Under this cooperation, the hotel has two types of customers: $t$-customer who books a room by phone, in person, or through the hotel's own website and w-customer who books a room through third-party websites. The hotel conducts price parity among all selling parties as a strategy to attract customers [27]. Price parity means that hotels charge the same room rate $p$ per day to all customers from different distribution channels. No booking fees are charged when making reservations. The variable cost of each occupied room is $c$, while the fixed cost of the hotel is $F$.

In this study, the agency model is applied in the cooperation between the hotel and third-party websites, in which the hotel pays a commission rate to third-party websites for each room sold [4,50,51]. The room inventory of hotels is usually not transparent to third-party websites under the agency model. In practice, the commission is usually given as a percentage of the room rate [27], that is, $\omega_{i}=\theta_{i} p$, $i=1,2, \ldots, n$, and $\theta_{i}$ differs according to third-party websites.

The total demand of the hotel, including that of t-customers and w-customers, is denoted as $D$, where $D$ is given as $D=a-b p+\varepsilon$. The expected part of the demand is influenced by room rate $p$, whereas stochastic component $\varepsilon$ is independent of room rate. Random variable $\varepsilon$ is distributed continuously with probability density function $f(\varepsilon)$ and cumulative distribution function $F(\varepsilon)$.

As the hotel and third-party websites have the same customer market, they compete with each other on customer resources and exert sales effort to encourage customers to book rooms through their own ordering system [52]. For example, some hotels offer special services, such as breakfast for t-customers 
only. Third-party websites, on the other hand, provide customers with various travel information, which is highly convenient for the customers. Ctrip, the largest online travel agency in Mainland China, also provides cash back to w-customers who check-in successfully [52]. The effort levels of the hotel and website $i$ are denoted respectively as $e_{0}$ and $e_{i}, i=1,2, \ldots, n$. Consequently, the market shares of the hotel and website $i$ are calculated respectively as $e_{0} /\left(e_{0}+\sum e_{i}\right)$ and $e_{i} /\left(e_{0}+\sum e_{i}\right)$, as shown in Figure 1. The effort will incur a cost of $h\left(e_{0}\right)$ and $h\left(e_{i}\right)$ to the hotel and third-party websites $i$, respectively. According to [52-55], effort cost is increasingly convex with effort level. Therefore, we assume that the effort cost for the hotel and website $i$ is $k e_{0}^{2} / 2$ and $k e_{i}^{2} / 2$, respectively, where $k>0$ is the investment coefficient.

\subsection{Overbooking and Expected Profits}

Some customers suddenly cancel their bookings at the last minute or do not show up on the target date without notifying the hotel because of some personal reasons such as a change in the trip or work schedule update. Hence, to improve its occupancy rate, the hotel implements an overbooking strategy and sets an overbooking level of $l$, which is defined as the number of accepted room bookings beyond hotel capacity. Consequently, $C+l$ room bookings can be accepted at most by the hotel. Integrate all customers as a whole and its show-up rate is denoted as $\beta$, where $\beta \in\left[\beta_{1}, \beta_{2}\right]$, and its probability density function and cumulative distribution function are $g(\beta)$ and $G(\beta)$, respectively. This assumption is widely applied in academic research and does not influence the results [56]. Therefore, $\beta(C+l)$ customers will show up at the hotel reception on the target date if $C+l$ customers make room reservations.

However, the overbooking strategy of the hotel may lead to over sales [14]. When the number of arriving customers on the target date exceeds room capacity, some will be denied check-in. Hence, to prevent bad publicity through word of mouth and maintain a good reputation, the hotel will attempt to placate the denied customers through various means [41]. For instance, hotels would recommend the denied customers to other hotels that can accommodate them or provide a free one-night stay on a future date. In this study, the hotel provides each denied customer with a compensation rate $v=r p$, which increases with room rate, and $r$ is compensation coefficient.

With the overbooking policy, the expected demand of the hotel $x$, which includes both $\mathrm{t}-$ and w-customers, is given as follows. First, when the number of room bookings is smaller than room capacity, that is, $D \leq C$, the hotel accepts all bookings and $\beta D$ arriving customers are accommodated on the target date. Second, when the number of room bookings is within the range of $C$ to $C+l$, i.e., $C<D<C+l$, the hotel accepts all room bookings, and $\beta D$ customers arrive on the target date. The hotel accommodates all customers if $\beta D \leq C$; otherwise, $\beta D-C$ are denied. Third, when the number of room bookings is greater than $C+l$, the hotel only accepts $C+l$ room bookings. The hotel accommodates all $\beta(C+l)$ customers on the target date if $\beta(C+l) \leq C$; otherwise, $\beta(C+l)-C$ of the bookings are denied. Thus, the expected demand for the target date is given as

$$
x=\underset{\varepsilon, \beta \mid D \leq C}{E}[\beta D]+\underset{\varepsilon, \beta \mid C<D<C+l}{E}[\min \{\beta D, C\}]+\underset{\varepsilon, \beta \mid D \geq C+l}{E}[\min \{\beta(C+l), C\}]
$$

where $D=a-b p+\varepsilon$. 
The expected demand of the third-party website $i$ is given as

$$
x_{i}=x e_{i} /\left(e_{0}+\sum e_{i}\right), i=1,2, \ldots, n
$$

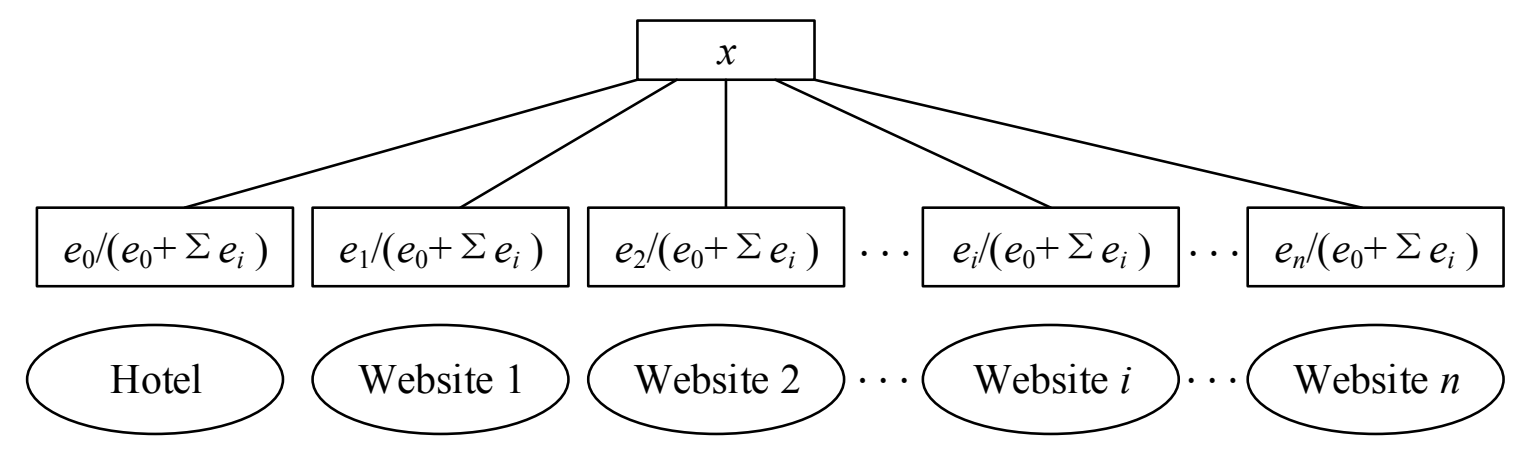

Figure 1. Market shares of the hotel and third-party websites.

As the expected demands are observed, the expected profit of the hotel is realized as follows:

$$
\pi_{0}=(p-c) x-\sum \omega_{i} x_{i}-v\left(\underset{\varepsilon, \beta \mid C<D<C+l}{E}[\beta D-C]^{+}+\underset{\varepsilon, \beta \mid D \geq C+l}{E}[\beta(C+l)-C]^{+}\right)-k e_{0}^{2} / 2-F
$$

where $D=a-b p+\varepsilon$. The first part is revenue obtained from accommodated customers. The second part represents total commission paid to third-party websites. The third part is total compensation fee paid to denied customers. The fourth and fifth parts represent effort cost and fixed cost, respectively.

The expected profit of third-party website $i$ is given as

$$
\pi_{i}=\omega_{i} x_{i}-k e_{i}^{2} / 2, i=1,2, \ldots, n
$$

Optimal decisions for a hotel will be affected by various factors, such as seasons, weathers, or even social activities [8,57], however, this model can be applied for various hotels with diverse capacities by assuming a fixed demand function.

\section{Results and Discussion}

\subsection{Solution Methodology}

This section discusses the optimal solution for the cooperation problem described previously. The interaction between the hotel and third-party websites is modeled as a Stackelberg game, which is used to describe the competitive relationship between two or more members. The member who acts first to make decisions is known as the leader, and the one who acts according to the leader's decisions is known as the follower [58,59]. In recent years, the Stackelberg game has been widely adopted in the service industry to depict the cooperative relationship between services providers and their partners [52,60,61]. For example, Huang et al. [62] apply this game theory to analyze the relationship between two hotels and a travel agency and study impacts of different power structures on room rate. In the present study, the hotel is the leader and $n$ third-party websites are the followers. In providing room reservation service cooperatively, the hotel first determines its room rate and overbooking level. Then commission rates paid to the third-party websites are given because commission rate is $\theta_{i}$ percentage of the room rate. Subsequently, the third-party websites determine their sales effort according to the commission 
rates. The Nash game is played among $n$ third-party websites, which is used to describe the competitive relationship of members who act simultaneously [63]. The multiple websites compete for finite room capacity and determine their effort levels.

The sequence of events involved in the cooperation between the hotel and third-party websites are as follows:

Step 1: The hotel determines overbooking level $l$ and room rate $p$.

Step 2: Third-party website $i$ determines effort level $e_{i}$ according to commission rate $\omega_{i}=\theta_{i} p$.

Step 3: The hotel and third-party websites accept room bookings.

Step 4: The hotel accommodates all arriving customers on the target date when its capacity is sufficient; otherwise, some of the arriving customers are denied and are provided a compensation rate of $v$.

The optimal decisions can be obtained through backward induction, with which the followers' decisions are analyzed first and then the leader's decisions are obtained. First, for a given $l$ and $p$, website $i$ maximizes its profit by solving $\max _{e_{i}} \pi_{i}$. From the first-order condition of Equation (4) on $e_{i}$, the unique effort level of website $i$ is given by

$$
\omega_{i} x\left(e_{0}+\sum_{j \neq i} e_{j}\right)=k e_{i}\left(e_{0}+\sum e_{i}\right)^{2}, i=1,2, \ldots, n
$$

Second, with knowledge of the website's reaction to its decisions, the hotel maximizes its profit by determining the optimal overbooking level and room rate $\left(l^{*}, p^{*}\right)$ by solving the following problem:

$$
\begin{aligned}
\max _{(l, p)} \pi_{0}=(p-c) x-\sum \omega_{i} x_{i}-v\left(\underset{\varepsilon, \beta \mid C<D<C+l}{E}[\beta D-C]^{+}+\underset{\varepsilon, \beta \mid D \geq C+l}{E}[\beta(C+l)-C]^{+}\right)-\frac{k}{2} e_{0}^{2}-F \\
\text { s.t. }\left\{\begin{array}{l}
D=a-b p+\varepsilon \\
x=\underset{\varepsilon, \beta \mid D \leq C}{E}[\beta D]+\underset{\varepsilon, \beta \mid C<D<C+l}{E}[\min \{\beta D, C\}]+\underset{\varepsilon, \beta \mid D \geq C+l}{E}[\min \{\beta(C+l), C\}] \\
x_{i}=x e_{i} /\left(e_{0}+\sum e_{i}\right), i=1,2, \ldots, n \\
\omega_{i} x\left(e_{0}+\sum_{j \neq i} e_{j}\right)=k e_{i}\left(e_{0}+\sum e_{i}\right)^{2}, i=1,2, \ldots, n
\end{array}\right.
\end{aligned}
$$

By solving the above problem, the optimal overbooking level $l^{*}$ and room rate $p^{*}$ of the hotel are obtained. Substitute them into Equation (5), the optimal effort levels of the third-party websites are then calculated. Consequently, the optimal profits of the hotel and website are obtained as $\pi_{0}^{*}$ and $\pi_{i}^{*}$, respectively. However, since distributions of customer demand and show-up rate are not known, a closed-form solution of the model cannot be obtained. A numerical example is shown in the next subsection to illustrate the optimal solutions.

\subsection{Numerical Experiments}

This section conducts numerical analysis of one hotel and two third-party websites based on the mathematical model constructed in Section 3 and the solution methodology given in Section 4.1. The hotel determines the room rate and overbooking level by maximizing its profit. As $\omega_{i}=\theta_{i} p$, 
commission paid to website $i$ is given once the room rate is determined. Website $i, i=1,2$, then determines its effort level with its maximal profit. The numerical example illustrates the equilibrium solutions in previous sections and provides insights into hotel pricing and overbooking strategies while under an agreement with cooperative third-party websites.

For convenience, and without affecting the findings, the show-up rate of customers $\beta$ is uniformly distributed over $[0.8,1]$, while $\varepsilon$ follows a normal distribution with mean value $\mu=0$ and standard deviation $\sigma=45$. Other values of basic parameters are given in Table 1. Based on the these values of parameters, optimal pricing and overbooking strategies of the hotel and optimal effort levels of the third-party websites can be calculated through simulations with a genetic algorithm using Matlab $2011 \mathrm{~b}\left({ }^{\circledR} 7.13 .0 .564\right)$. The details can be found in Table 2 .

Table 1. Values of parameters.

\begin{tabular}{cccccccccccc}
\hline Parameters & $\boldsymbol{n}$ & $\boldsymbol{C}$ & $\boldsymbol{c}$ & $\boldsymbol{F}$ & $\boldsymbol{a}$ & $\boldsymbol{b}$ & $\boldsymbol{e}_{\mathbf{0}}$ & $\boldsymbol{\theta}_{\mathbf{1}}$ & $\boldsymbol{\theta}_{\mathbf{2}}$ & $\boldsymbol{k}$ & $\boldsymbol{r}$ \\
\hline Values & 2 & 150 & 15 & 4000 & 500 & 3.2 & 30 & 0.12 & 0.15 & 1 & 1 \\
\hline
\end{tabular}

Note: $n=$ the number of websites; $C=$ room capacity; $c=$ variable cost of each occupied room; $F=$ fixed cost of the hotel; $a=$ total demand of the market; $b=$ price elastic coefficient; $e_{0}=$ effort level of the hotel; $\theta_{i}=$ commission coefficient for website $i, i=1,2 ; k=$ investment coefficient. $a$ and $b$ are calculated from array $(p, E[D])=(100,180)$ and $(p, E[D])=(150,20)$.

The results in Table 2 indicate that to maximize its occupancy rate, the hotel will overbook 13 rooms in anticipation of last-minute cancellations and no-shows of customers. Furthermore, a higher commission rate $\left(\theta_{2}>\theta_{1}\right)$ will result in a higher effort level from the website $\left(e_{2}>e_{1}\right)$. In this example, Website 2 exerts more effort on room sales and obtains higher market share $\left(x_{2}>x_{1}\right)$ and consequently a richer profit $\left(\pi_{2}>\pi_{1}\right)$.

Table 2. Optimal decisions and profits.

\begin{tabular}{|c|c|c|c|c|c|c|c|c|c|c|c|}
\hline$p$ & $l$ & $e_{1}$ & $e_{2}$ & $\omega_{1}$ & $\omega_{2}$ & $x$ & $x_{1}$ & $x_{2}$ & $\pi_{0}$ & $\pi_{1}$ & $\pi_{2}$ \\
\hline 107 & 13 & 17.65 & 20.73 & 12.84 & 16.05 & 126.73 & 32.71 & 38.41 & 6035.9 & 264.2 & 401.7 \\
\hline
\end{tabular}

Note: $p=$ room rate; $l=$ overbooking level set by the hotel; $e_{i}=$ effort level of website $i ; \omega_{i}=$ commission rate paid to website $i ; x=$ expected demand of the hotel; $x_{i}=$ market share of website $i ; \pi_{0}=$ profit of the hotel; $\pi_{i}=$ profit of website $i, i=1,2$.

A sensitivity analysis is conducted to further address the effects of parameters on decisions and profits of the hotel and third-party websites. Practical implications are analyzed based on the results obtained. Based on basic values in Table 1, Table 3 depicts the effects of compensation coefficient on optimal decisions, while Table 4 shows the effects of fluctuations in customer demand. Table 5 illustrates the effects of hotel effort level on optimal solutions. Table 6 shows the effects of room capacity.

Table 3 indicates that compensation coefficient does not have significant effect on hotel pricing strategy. However, the overbooking level decreases sharply when the compensation coefficient increases because the hotel attempts to reduce the expected demand to lessen the necessity to pay compensation fees to denied customers. On the other hand, along with the increase in compensation coefficient, the third-party websites will lower their effort levels although commission rates paid by the hotel remain unchanged. 
Table 3. Effects of compensation coefficient on decisions and profits.

\begin{tabular}{ccccccccccccc}
\hline $\boldsymbol{r}$ & $\boldsymbol{p}$ & $\boldsymbol{l}$ & $\boldsymbol{e}_{\mathbf{1}}$ & $\boldsymbol{e}_{\mathbf{2}}$ & $\boldsymbol{\omega}_{\mathbf{1}}$ & $\boldsymbol{\omega}_{\boldsymbol{2}}$ & $\boldsymbol{x}$ & $\boldsymbol{x}_{\mathbf{1}}$ & $\boldsymbol{x}_{\mathbf{2}}$ & $\boldsymbol{\pi}_{\boldsymbol{0}}$ & $\boldsymbol{\pi}_{\mathbf{1}}$ & $\boldsymbol{\pi}_{\mathbf{2}}$ \\
\hline 0.5 & 106 & 20 & 17.78 & 20.88 & 12.72 & 15.90 & 129.55 & 33.55 & 39.39 & 6136.3 & 268.7 & 408.4 \\
1 & 107 & 13 & 17.65 & 20.73 & 12.84 & 16.05 & 126.73 & 32.71 & 38.41 & 6035.9 & 264.2 & 401.7 \\
1.5 & 107 & 10 & 17.59 & 20.66 & 12.84 & 16.05 & 125.95 & 32.46 & 38.12 & 5980.9 & 262.1 & 398.5 \\
2 & 107 & 8 & 17.54 & 20.60 & 12.84 & 16.05 & 125.34 & 32.26 & 37.89 & 5945.9 & 260.4 & 396.0 \\
2.5 & 107 & 7 & 17.51 & 20.57 & 12.84 & 16.05 & 125.00 & 32.15 & 37.76 & 5921.5 & 259.5 & 394.6 \\
\hline
\end{tabular}

Table 4. Effects of demand fluctuations on decisions and profits.

\begin{tabular}{ccccccccccccc}
\hline $\boldsymbol{\delta}$ & $\boldsymbol{p}$ & $\boldsymbol{l}$ & $\boldsymbol{e}_{\mathbf{1}}$ & $\boldsymbol{e}_{\mathbf{2}}$ & $\boldsymbol{\omega}_{\mathbf{1}}$ & $\boldsymbol{\omega}_{\mathbf{2}}$ & $\boldsymbol{x}$ & $\boldsymbol{x}_{\mathbf{1}}$ & $\boldsymbol{x}_{\mathbf{2}}$ & $\boldsymbol{\pi}_{\mathbf{0}}$ & $\boldsymbol{\pi}_{\mathbf{1}}$ & $\boldsymbol{\pi}_{\mathbf{2}}$ \\
\hline 25 & 107 & 13 & 18.22 & 21.38 & 12.84 & 16.05 & 133.83 & 35.04 & 41.11 & 6618.3 & 283.9 & 431.2 \\
35 & 107 & 13 & 17.94 & 21.06 & 12.84 & 16.05 & 130.29 & 33.88 & 39.76 & 6327.6 & 274.0 & 416.5 \\
45 & 107 & 13 & 17.65 & 20.73 & 12.84 & 16.05 & 126.73 & 32.71 & 38.41 & 6035.9 & 264.2 & 401.7 \\
55 & 106 & 13 & 17.39 & 20.42 & 12.72 & 15.90 & 124.63 & 31.95 & 37.54 & 5746.5 & 255.3 & 388.3 \\
65 & 106 & 13 & 17.10 & 20.09 & 12.72 & 15.90 & 121.15 & 30.83 & 36.23 & 5465.7 & 246.0 & 374.2 \\
\hline
\end{tabular}

Table 4 indicates that fluctuations in total demand have a slight effect on pricing and overbooking strategies of the hotel but a strong effect on hotel profit because a larger deviation in customer demand results in smaller expected demand for the hotel. Thus, lower expected demand leads to lower hotel profit. As customer demand fluctuates violently, the third-party websites exert a lower effort level in room sales. Hence, the third-party websites also obtain lower profits.

Table 5 shows that under a given market demand, the effort level of the hotel redistributes market shares among the hotel and third-party websites but has no effect on hotel pricing and overbooking strategies. The hotel gains a larger market share by exerting more sales effort, which in reverse leads to a smaller market share for the third-party websites. Thus, the profit of the hotel increases, whereas that of the websites decreases.

Table 5. Effects of hotel effort level on decisions and profits.

\begin{tabular}{ccccccccccccc}
\hline $\boldsymbol{e}_{\mathbf{0}}$ & $\boldsymbol{p}$ & $\boldsymbol{l}$ & $\boldsymbol{e}_{\mathbf{1}}$ & $\boldsymbol{e}_{\mathbf{2}}$ & $\boldsymbol{\omega}_{\mathbf{1}}$ & $\boldsymbol{\omega}_{\boldsymbol{2}}$ & $\boldsymbol{x}$ & $\boldsymbol{x}_{\mathbf{1}}$ & $\boldsymbol{x}_{\mathbf{2}}$ & $\boldsymbol{\pi}_{\mathbf{0}}$ & $\boldsymbol{\pi}_{\mathbf{1}}$ & $\boldsymbol{\pi}_{\boldsymbol{2}}$ \\
\hline 20 & 107 & 13 & 18.64 & 21.63 & 12.84 & 16.05 & 126.73 & 39.20 & 45.48 & 6089.2 & 329.5 & 496.0 \\
25 & 107 & 13 & 18.15 & 21.20 & 12.84 & 16.05 & 126.73 & 35.75 & 41.74 & 6081.0 & 294.3 & 445.3 \\
30 & 107 & 13 & 17.65 & 20.73 & 12.84 & 16.05 & 126.73 & 32.71 & 38.41 & 6035.9 & 264.2 & 401.7 \\
35 & 107 & 13 & 17.15 & 20.24 & 12.84 & 16.05 & 126.73 & 30.02 & 35.43 & 5955.8 & 238.4 & 363.8 \\
40 & 107 & 13 & 16.66 & 19.74 & 12.84 & 16.05 & 126.73 & 27.63 & 32.75 & 5842.1 & 216.0 & 330.7 \\
\hline
\end{tabular}

As shown in Table 6, a hotel with a larger room capacity will set a lower room rate to increase customer demand and then improve room occupancy rate. The hotel also tends to set a higher overbooking level to reduce the number of unoccupied rooms, resulting in an increase in expected demand. Effort levels of the third-party websites increase with room capacity for the same reason. Hence, the expansion in room capacity will increase profits for the hotel and third-party websites. 
Table 6. Effects of room capacity on decisions and profits.

\begin{tabular}{ccccccccccccc}
\hline $\boldsymbol{C}$ & $\boldsymbol{p}$ & $\boldsymbol{l}$ & $\boldsymbol{e}_{\mathbf{1}}$ & $\boldsymbol{e}_{\mathbf{2}}$ & $\boldsymbol{\omega}_{\mathbf{1}}$ & $\boldsymbol{\omega}_{\mathbf{2}}$ & $\boldsymbol{x}$ & $\boldsymbol{x}_{\mathbf{1}}$ & $\boldsymbol{x}_{\mathbf{2}}$ & $\boldsymbol{\pi}_{\mathbf{0}}$ & $\boldsymbol{\pi}_{\mathbf{1}}$ & $\boldsymbol{\pi}_{\mathbf{2}}$ \\
\hline 130 & 111 & 12 & 16.73 & 19.67 & 13.32 & 16.65 & 111.46 & 28.08 & 33.02 & 5168.3 & 234.1 & 356.3 \\
140 & 109 & 12 & 17.20 & 20.21 & 13.08 & 16.35 & 119.03 & 30.37 & 35.69 & 5621.6 & 249.3 & 379.2 \\
150 & 107 & 13 & 17.65 & 20.73 & 12.84 & 16.05 & 126.73 & 32.71 & 38.41 & 6035.9 & 264.2 & 401.7 \\
160 & 105 & 14 & 18.06 & 21.19 & 12.60 & 15.75 & 134.27 & 35.01 & 41.09 & 6411.7 & 278.1 & 422.6 \\
170 & 103 & 15 & 18.42 & 21.61 & 12.36 & 15.45 & 141.66 & 37.27 & 43.71 & 6749.9 & 290.9 & 441.9 \\
\hline
\end{tabular}

\section{Extension: Profit Improvement by Overbooking Strategy}

This section explores profit improvement for the hotel and $n$ third-party websites based on the overbooking strategy. As a benchmark, the scenario in which the overbooking strategy is not adopted by the hotel is set. In the benchmark, the hotel determines its optimal room rate by maximizing its profit. Once room rate is determined, the commission rates paid to the third-party websites are also obtained. Subsequently, the websites determine their effort levels with their maximal profits.

The expected demand of the benchmark scenario is given as

$$
x^{B}=\underset{\varepsilon, \beta \mid D \leq C}{E}[\beta D]+\underset{\varepsilon, \beta \mid D>C}{E}[\beta C]
$$

where $D=a-b p^{B}+\varepsilon$.

The market share for third-party website $i$ is obtained as

$$
x_{i}^{B}=x^{B} e_{i}^{B} /\left(e_{0}+\sum e_{i}^{B}\right), i=1,2, \ldots, n
$$

According to the cooperation problem described in Section 3, the expected profits of the hotel and third-party website $i$, without the overbooking strategy, are given as follows:

$$
\pi_{0}^{B}=\left(p^{B}-c\right) x^{B}-\sum \omega_{i}^{B} x_{i}^{B}-k e_{0}^{2} / 2-F, \pi_{i}^{B}=\omega_{i}^{B} x_{i}^{B}-k\left(e_{i}^{B}\right)^{2} / 2, i=1,2, \ldots, n
$$

where $\omega_{i}^{B}=\theta_{i} p^{B}, i=1,2, \ldots, n$.

The solving process is similar to that described in Section 4.1. First, given the hotel room rate, third-party website $i$ determines its effort level as

$$
\omega_{i}^{B} x^{B}\left(e_{0}+\sum_{j \neq i} e_{j}^{B}\right)=k e_{i}^{B}\left(e_{0}+\sum e_{i}^{B}\right)^{2}, i=1,2, \ldots, n
$$

Second, with knowledge of the decision of third-party website $i$, the hotel determines its optimal room rate by solving the following problem:

$$
\begin{gathered}
\max _{p^{B}} \pi_{0}^{B}=\left(p^{B}-c\right) x^{B}-\sum \omega_{i}^{B} x_{i}^{B}-k e_{0}^{2} / 2-F \\
\text { s.t. }\left\{\begin{array}{l}
D=a-b p^{B}+\varepsilon \\
x^{B}=\underset{\varepsilon, \beta \mid D \leq C}{E}[\beta D]+\underset{\varepsilon, \beta \mid D>C}{E}[\beta C] \\
x_{i}^{B}=x^{B} e_{i}^{B} /\left(e_{0}+\sum e_{i}^{B}\right), i=1,2, \ldots, n \\
\omega_{i}^{B} x^{B}\left(e_{0}+\sum_{j \neq i} e_{j}^{B}\right)=k e_{i}^{B}\left(e_{0}+\sum e_{i}^{B}\right)^{2}, i=1,2, \ldots, n
\end{array}\right.
\end{gathered}
$$


By solving this problem, the optimal room rate is obtained. Substitute it into Equation (7), the optimal effort levels of the third-party websites can be calculated. Then the optimal profits of the hotel and third-party website $i$ are given as $\pi_{0}^{B^{*}}$ and $\pi_{i}^{B^{*}}$, respectively. The improved profits due to the overbooking strategy for the hotel and third-party website $i$ are denoted as $\Delta \pi_{0}=\pi_{0}^{*}-\pi_{0}^{B^{*}}$ and $\Delta \pi_{i}=\pi_{i}^{*}-\pi_{i}^{B^{*}}$, respectively.

A numerical example is displayed to illustrate optimal results in the benchmark and to enable a better understanding of the model. One hotel and two third-party websites are considered, and the basic values of other parameters are identical to those given in Table 1. The optimal decisions of the hotel and third-party websites as well as profit improvement based on overbooking strategy are shown in Table 7.

Table 7. Profit improvement based on overbooking strategy.

\begin{tabular}{cccccccccc}
\hline & $\boldsymbol{p}$ & $\boldsymbol{e}_{\mathbf{1}}$ & $\boldsymbol{e}_{\mathbf{2}}$ & $\boldsymbol{x}$ & $\boldsymbol{x}_{\mathbf{1}}$ & $\boldsymbol{x}_{\mathbf{2}}$ & $\boldsymbol{\pi}_{\mathbf{0}}$ & $\boldsymbol{\pi}_{\mathbf{1}}$ & $\boldsymbol{\pi}_{\mathbf{2}}$ \\
\hline Benchmark scenario & 108 & 17.25 & 20.27 & 120.82 & 36.23 & 42.58 & 5792.5 & 251.0 & 381.8 \\
Overbooking scenario & 107 & 17.65 & 20.73 & 126.73 & 38.31 & 45.00 & 6035.9 & 264.2 & 401.7 \\
Profit improvement & - & - & - & - & - & - & $4.20 \%$ & $5.26 \%$ & $5.21 \%$ \\
\hline
\end{tabular}

Table 7 reveals the following findings. First, with overbooking strategy, the expected demand is larger than that in the benchmark scenario. In other words, overbooking strategy increases hotel demand. Second, an overbooking strategy improves the profits of the third-party websites, with a higher proportion at 5.26\% for Website 1 and 5.21\% for Website 2 than that of the hotel at only $4.20 \%$. This result can be attributed to the third-party websites bearing no risk of over sale caused by overbooking, whereas the hotel has to pay a compensation fee to each denied customer. Finally, third-party websites that exert more effort to make sales do not always benefit more from the overbooking strategy. In the numerical example, Website 2 who exerts more effort in room sales only achieves an improvement of 5.21\% in profit, which is lower than 5.26\% for Website 1 .

\section{Conclusions}

Hotels adopt overbooking strategy to accept more room bookings to hedge against last-minute cancellations and no-shows at the price of a compensation fee paid to denied customers, and cooperate with third-party websites to attract more customers at the price of commission. This study investigates pricing and overbooking strategies of a hotel in cooperation with multiple third-party websites by discussing cooperation and competition relationship between the hotel and third-party websites simultaneously. We also explore the effect of a hotel overbooking strategy on this cooperation process.

This study concludes with several important findings. First, compensation coefficient has a slight effect on hotel pricing decision. However, with the increase of compensation coefficient, the hotel will set a lower overbooking level to reduce the risk of over sale. As a result, the third-party website would exert lower effort level in room sales along with the increase of compensation coefficient. Second, under a given market demand, the effort level of the hotel will not affect its pricing and overbooking strategies and results only in a redistribution of the market shares among the hotel and third-party websites. Along with the increase in hotel effort level, the market shares of the third-party websites 
will decrease resulting from an increase in hotel market share. Third, by adopting overbooking strategy, the hotel achieves more profit improvement than the website (243.4 for the hotel, versus 13.2 for Website 1 and 19.9 for Website 2). Nevertheless, a hotel overbooking strategy increases the profits of Websites 1 and 2 by a proportion of $5.26 \%$ and $5.21 \%$, respectively, but only $4.20 \%$ for the hotel. Due to the fact that the third-party websites are not responsible for over sale caused by overbooking, they benefit more from this strategy than the hotel. Results also show that cooperative websites getting richer commission and exerting more sales effort do not always benefit more from the overbooking strategy of hotels.

The conclusions obtained yield significant management implications for hotels and third-party websites. First, over sale caused by overbooking will harm customer's goodwill, cause revenue loss to hotels and damage a hotel's reputation [14,64]. Consequently, hotels should make an appropriate overbooking strategy by considering the expense of compensating denied customers. The present paper indicates hotels how to determine the optimal overbooking level under given compensation to denied customers. To placate denied customers, hotels should give priority to them or provide them with free stay in the future to compensate them. Second, as hotels cooperate with third-party websites on room reservation, they inevitably compete with each other on the customer source because of the same customer market [48]. Therefore, both hotels and third-party websites should exert more efforts to encourage customers to make reservation directly through their own distribution channels. For example, hotels can make marketing effort by providing breakfast to h-customers only to encourage them to book rooms through their brand website. Alternatively, some third-party websites (such as Ctrip in Mainland China) offer cash back to customers who make room reservations through their webpage and check in successfully. Finally, as shown in the numerical example, larger room capacity and higher room rate of the cooperative hotels will result in a richer profit for the third-party websites. Thus, third-party websites should cooperate with luxury and large-scale hotels to earn more profits.

This study is limited in several aspects, on which future studies could focus. First, the demand for hotels change over time in actual settings, and dynamic programming may be a desirable method to address this problem. Second, a non-performance penalty imposed on the hotel is discussed; that is, the hotel pays compensation fees to denied customers for their inability to accommodate them. However, imposing early departure and no-show penalties on customers are other effective methods to hedge against last-minute cancellations and no-shows, and improve occupancy rate. Finally, all hotel rooms are assumed identical in this study. Different types of rooms may be considered for future research, and an upgrade or downgrade strategy may also be effective in increasing the total occupancy rate of hotels.

\section{Acknowledgments}

Thank the anonymous reviewers for constructive suggestions, which improves the quality of the paper. This work was supported by the National Natural Science Foundation of China under Grant 71271197; the Foundation for Innovative Research Groups of the National Natural Science Foundation of China under Grant 71121061; and the Foundation for International Cooperation and Exchange of the National Natural Science Foundation of China under Grant 71110107024. We appreciate 
Yanhua Chen, who is from Department of Biostatistics, School of Public Health and Health Professions-University at Buffalo for English corrections.

\section{Author Contributions}

Liuyi Ling proposed the idea and conceived the experiments; Yufeng Dong developed the model, performed the experiments, analyzed the data and wrote the paper. Both authors have read and approved the final manuscript.

\section{Conflicts of Interest}

The authors declare no conflict of interest.

\section{References}

1. Bitran, G.R.; Mondschein, S.V. An application of yield management to the hotel industry considering multiple day stays. Oper. Res. 1995, 43, 427-443.

2. Chatwin, R.E. Continuous-time airline overbooking with time-dependent fares and refunds. Transp. Sci. 1999, 33, 182-191.

3. Easingwood, C.J. New product development for service companies. J. Prod. Innov. Manag. 1986, 3, 264-275.

4. Vargo, S.L.; Lusch, R.F. The four service marketing myths remnants of a goods-based, manufacturing model. J. Serv. Res. 2004, 6, 324-335.

5. De Chernatony, L.; Dall'Olmo Riley, F. Experts' views about defining services brands and the principles of services branding. J. Bus. Res. 1999, 46, 181-192.

6. Tang, K.; Zairi, M. Benchmarking quality implementation in a service context: A comparative analysis of financial services and institutions of higher education. Part I: financial services sector. Total Qual. Manag. 1998, 9, 407-420.

7. Ladany, S.P. Optimal market segmentation of hotel rooms-The non-linear case. Omega 1996, 24, 29-36.

8. Guo, X.; Ling, L.; Yang, C.; Li, Z.; Liang, L. Optimal pricing strategy based on market segmentation for service products using online reservation systems: An application to hotel rooms. Int. J. Hosp. Manag. 2013, 35, 274-281.

9. Klophaus, R.; Pölt, S. Airline overbooking with dynamic spoilage costs. J. Revenue Pricing Manag. 2007, 6, 9-18.

10. Mauri, A. Yield management and perceptions of fairness in the hotel business. Int. Rev. Econ. 2007, 54, 284-293.

11. Barth, J.E. Yield management: Opportunities for private club managers. Int. J. Contemp. Hosp. Manag. 2002, 14, 136-141.

12. Roennevig, M.; Media, D. What Does Overbooked at a Hotel Mean? Available online: http://traveltips.usatoday.com/overbooked-hotel-mean-108088.html (accessed on 13 April 2015).

13. Mauri, A.G. Hotel Revenue Management: Principles and Practices; McGraw-Hill: Milan, Italy, 2012. 
14. Vinod, B. Unlocking the value of revenue management in the hotel industry. J. Revenue Pricing Manag. 2004, 3, 178-190.

15. Zhang, X.; Wang, P.; Wang, Y.; Wang, G. Regulatory Focus and Recovery Fit in Airline Overbooking. In Proceedings of the 2010 IEEE International Conference on Industrial Engineering and Engineering Management (IEEM), Macao, China, 7-10 December 2010; pp. 758-761.

16. Hwang, J.; Wen, L. The effect of perceived fairness toward hotel overbooking and compensation practices on customer loyalty. Int. J. Contemp. Hosp. Manag. 2009, 21, 659-675.

17. Grönroos, C. Service Management and Marketing: Customer Management in Service Competition, 2nd ed.; John Wiley \& Sons Ltd.: Chichester, UK, 2000; pp. 24-25.

18. Zeithaml, V.A.; Bitner, M.J.; Gremler, D.D. Services Marketing: Integrating Customer Focus across the Firm, International ed.; McGraw-Hill Education: Singapore, 2006.

19. Garcés, S.A.; Gorgemans, S.; Sánchez, A.M.N.; Pérez, M.P. Implications of the Internet-An analysis of the Aragonese hospitality industry, 2002. Tour. Manag. 2004, 25, 603-613.

20. Gregory, S.; Breiter, D. Leveling the playing field: E-marketing's impact on lodging operations. J. Hosp. Leis. Mark. 2001, 7, 45-60.

21. Kim, D.J.; Kim, W.G.; Han, J.S. A perceptual mapping of online travel agencies and preference attributes. Tour. Manag. 2007, 28, 591-603.

22. Theodosiou, M.; Katsikea, E. Antecedents and performance of electronic business adoption in the hotel industry. Eur. J. Mark. 2012, 46, 258-283.

23. Ma, C. E-collaboration: A universal key to solve fierce competition in tourism industry? Int. Bus. Res. 2009, 1, P65.

24. Medina-Muñoz, D.; García-Falcón, J.M. Successful relationships between hotels and agencies. Ann. Tour. Res. 2000, 27, 737-762.

25. Ivanov, S. Optimal Overbooking Limits for a 3-Room Type Hotel with Upgrade and Downgrade Constraints. Available online: http://ssrn.com/abstract=2190042 (accessed on 18 August 2013).

26. Noone, B.M.; Lee, C.H. Hotel overbooking: The effect of overcompensation on customers' reactions to denied service. J. Hosp. Tour. Res. 2011, 35, 334-357.

27. Toh, R.S.; Raven, P.; DeKay, F. Selling rooms: Hotels vs. third-party websites. Cornell Hosp. Q. 2011, 52, 181-189.

28. Jamal, T.B.; Getz, D. Collaboration theory and community tourism planning. Ann. Tour. Res. 1995, 22, 186-204.

29. Chathoth, P.K.; Olsen, M.D. Strategic alliances: A hospitality industry perspective. Int. J. Hosp. Manag. 2003, 22, 419-434.

30. Byrd, E.T. Stakeholders in sustainable tourism development and their roles: Applying stakeholder theory to sustainable tourism development. Tour. Rev. 2007, 62, 6-13.

31. Hadjinicola, G.C.; Panayi, C. The overbooking problem in hotels with multiple tour-operators. Int. J. Oper. Prod. Manag. 1997, 17, 874-885.

32. Baker, T.K. New Approaches to Yield Management: Comprehensive Overbooking/Allocation Heuristics for the Hotel Industry. Available online: http://sunzi.lib.hku.hk/ER/detail/hkul/2993390 (accessed on 18 August 2013). 
33. Lambert, C.U.; Lambert, J.M.; Cullen, T.P. The overbooking question: A simulation. Cornell Hotel Restaur. Adm. Q. 1989, 30, 14-20.

34. Weatherford, L.R.; Bodily, S.E. A taxonomy and research overview of perishable-asset revenue management: Yield management, overbooking, and pricing. Oper. Res. 1992, 40, 831-844.

35. Rothstein, M. Hotel overbooking as a markovian sequential decision process. Decis. Sci. 1974, 5, 389-404.

36. Ivanov, S. Dynamic overbooking limits for guaranteed and nonguaranteed hotel reservations. Tour. Today 2007, 7, 100-108.

37. Liberman, V.; Yechiali, U. On the hotel overbooking problem-An inventory system with stochastic cancellations. Manag. Sci. 1978, 24, 1117-1126.

38. Toh, R.S. An inventory depletion overbooking model for the hotel industry. J. Travel Res. 1985, 23, 24-30.

39. Toh, R.S.; Dekay, F. Hotel room-inventory management: An overbooking model. Cornell Hotel Restaur. Adm. Q. 2002, 43, 79-90.

40. Koide, T.; Ishii, H. The hotel yield management with two types of room prices, overbooking and cancellations. Int. J. Product. Econ. 2005, 93-94, 417-428.

41. Talluri, K.T.; van Ryzin, G.J. The Theory and Practice of Revenue Management; Springer Science \& Business Media: New York, NY, USA, 2006.

42. Karaesmen, I.; van Ryzin, G. Overbooking with substitutable inventory classes. Oper. Res. 2004, $52,83-104$.

43. Vinod, B. Distribution and revenue management: Origins and value proposition. J. Revenue Pricing Manag. 2009, 8, 117-133.

44. Ling, L.; Guo, X.; Liang, L. Optimal pricing strategy of a small or medium-sized hotel in cooperation with a web site. J. China Tour. Res. 2011, 7, 20-41.

45. Beritelli, P. Cooperation among prominent actors in a tourist destination. Ann. Tour. Res. 2011, 38, $607-629$.

46. Huang, Y.; Song, H.; Huang, G.Q.; Lou, J. A Comparative Study of Tourism Supply Chains with Quantity Competition. J. Travel Res. 2012, doi:10.1177/0047287512451138.

47. Buhalis, D. Relationships in the distribution channel of tourism: Conflicts between hoteliers and tour operators in the Mediterranean region. Int. J. Hosp. Tour. Adm. 2000, 1, 113-139.

48. Myung, E.; Li, L.; Bai, B. Managing the distribution channel relationship with e-Wholesalers: Hotel operators' perspective. J. Hosp. Market. Manag. 2009, 18, 811-828.

49. Narasimhan, K. Service management and marketing: Customer management in service competition. Manag. Serv. Qual. 2009, 19, 629-630.

50. Lee, H.A.; Guillet, B.D.; Law, R. An examination of the relationship between online travel agents and hotels: A case study of Choice Hotels International and Expedia. com. Cornell Hosp. Q. 2013, 54, 95-107.

51. Tso, A.; Law, R. Analysing the online pricing practices of hotels in Hong Kong. Int. J. Hosp. Manag. 2005, 24, 301-307.

52. Guo, X.; Zheng, X.; Ling, L.; Yang, C. Online coopetition between hotels and online travel agencies: From the perspective of cash back after stay. Tour. Manag. Perspect. 2014, 12, 104-112. 
53. Huang, Z.; Li, S.X. Co-op advertising models in manufacturer-retailer supply chains: A game theory approach. Eur. J. Oper. Res. 2001, 135, 527-544.

54. Little, J.D. Aggregate advertising models: The state of the art. Oper. Res. 1979, 27, 629-667.

55. Taylor, T.A. Supply chain coordination under channel rebates with sales effort effects. Manag. Sci. 2002, 48, 992-1007.

56. Kasilingam, R.G. An economic model for air cargo overbooking under stochastic capacity. Comput. Ind. Eng. 1997, 32, 221-226.

57. Fernández-Morales, A.; Mayorga-Toledano, M.C. Seasonal concentration of the hotel demand in Costa del Sol: A decomposition by nationalities. Tour. Manag. 2008, 29, 940-949.

58. Osborne, M.J.; Rubinstein, A. A Course in Game Theory; MIT Press: Cambridge, MA, USA, 1994.

59. Gibbons, R. Game Theory for Applied Economists; Princeton University Press: Princeton, NJ, USA, 1992.

60. Dong, Y.; Ling, L.; Guo, X. Travel package modeling: Optimal bidding strategy of tour operator to cooperative hotels. Asia Pac. J. Tour. Res. 2013, 19, 1-24.

61. Guo, X.; He, L. Tourism supply-chain coordination: The cooperation between tourism hotel and tour operator. Tour. Econ. 2012, 18, 1361-1376.

62. Huang, Y.; Wang, K.; Huang, G.Q. Price Competition under Different Power Structures of Hotels and Travel Agency in Tourism Supply Chain. Available online: http://www.aicit.org/ AISS/ppl/AISS3319PPL.pdf (accessed on 18 August 2012).

63. Guo, X.; Ling, L.; Dong, Y.; Liang, L. Cooperation contract in tourism supply chains: The optimal pricing strategy of hotels for cooperative third party strategic websites. Ann. Tour. Res. 2013, 41, 20-41.

64. DeKay, F.; Yates, B.; Toh, R.S. Non-performance penalties in the hotel industry. Int. J. Hosp. Manag. 2004, 23, 273-286.

(C) 2015 by the authors; licensee MDPI, Basel, Switzerland. This article is an open access article distributed under the terms and conditions of the Creative Commons Attribution license (http://creativecommons.org/licenses/by/4.0/). 